\title{
The Google Car: Driving Toward A Better Future?
}

Sharon L. Poczter, Cornell University, USA

Luka M. Jankovic, Cornell University, USA

\begin{abstract}
Google's dramatic ascent and subsequent domination in the past fifteen years of the technology and information industries has financially enabled Google to explore seemingly unrelated projects ranging from Google Mail to the Google Car. In particular, Google has invested a significant amount of resources in the Google Car, an integrated system that allows for the driverless operation of a vehicle. While initial reports indicate that the Google Car driverless automobile will be more safe and efficient than current vehicles, the Google Car is not without its critics. In particular, the existential threat that the car presents to several large industries, including the insurance, health care and construction industries, creates an additional challenge to the success of the Google Car well beyond the standard competitive threats from other established car manufacturers in the automobile industry, which begs the question, "Can the Google Car be successful?" With so many challenges above and beyond the competitive forces typically threatening long-term profitability, will the Google Car be able to create and sustain a competitive advantage for Google in the driverless car space?
\end{abstract}

Keywords: Competitive Advantage; Automobile Industry; Driverless Automobiles

\section{INTRODUCTION}

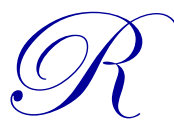

esearch into self-driving cars is not a new phenomenon. In the late 1950s, the first known thoughts on self-driving vehicles were described in Popular Mechanics magazine by a mechanic who argued that altering a roadster to both start itself and back itself into a driveway would be relatively straightforward. Later that year, a GM analyst revealed in Popular Science magazine that the company was already investigating embedding highways with cable and radio-control boxes as a means of developing an infrastructure to support driverless cars.

Despite all of the theoretical research into the subject, self-driving cars did not become a reality until 1968. The first physical breakthrough in driverless car technology was the design of a car that used sonar and gyroscopes to drive, steer, and brake an automobile. In 1968, The Cornell Aeronautical Laboratory created the "Urbmobile", an electric car that could be driven on the road but could also glide along a subway-style track that utilized roadside guides, magnetometers, magnetic nails, and internal computers.

The largest breakthrough came years later, however, with the announcement from Google, Inc. of the Google Car in 2010. With the distinctive sensor and camera nub lodged on top of a Toyota Prius, the Google Car quickly became operational and present on roads across the United States. Shortly thereafter, media coverage of the Google Car became increasingly prevalent in addition to promotional commercials demonstrating the benefits of the car (Google, 2013). While the benefits demonstrated in the videos seemed to be promising, the Google Car's entrance into the market seemed a far leap away from Google's core business.

\section{Google Inc.}

Google Inc. specializes in Internet-related services and products, with the mission to organize the world's information and make it universally accessible and useful. In 1998, Larry Page and Sergey Brin, two Stanford 
University computer science graduate students, created a search engine that uses back links, or incoming links, to a website or web page, to determine the importance and therefore rank individual web pages during a web query. Existing competitors, like Yahoo and AOL, on the other hand, were directories of other websites, organized in a hierarchy, as opposed to a searchable index of pages. This allows the Google search process to return more relevant results rather than simply a ranked list of preferred sites. In 1999, Google secured funding from Sequoia Capital and Kleiner Perkins Caufield \& Byers, Silicon Valley's two leading venture capital firms (Google, 2013). Only one year later, Google became the world's largest search engine with over a billion pages in its index, surpassing industry giants such as Yahoo. Google's dominance of the search market continues today as Google maintains a 67\% share of global searches (Miller, 2013).

While Google Inc. began as a company specializing in search, it quickly expanded into other product areas. In 2004, Google launched Gmail, an email client which became the world's largest email provider by 2012 with an estimated 425 million active users (Molla, 2012). Expanding into the online video domain, Google acquired YouTube in 2006 for $\$ 1.65$ billion, which reaches over 1 billion unique visitors each month. In 2008, Google launched Chrome, a web browser, and Android, an operating system for mobile devices. In both of these areas as well, Google dominates the market, with a $50 \%$ and $68 \%$ of the market share, respectively (Miller, 2013).

\section{The Google Car}

In 2010, Google announced that the prototype of a driverless car - the Google Car - was completed (Google, 2010). According to Google executives at the time, the goal of the Google Car was to "... help prevent traffic accidents, free up people's time and reduce carbon emissions by fundamentally changing car use" (Google, 2010). With a team assembled consisting of engineers with experience in vehicle technology from the DARPA Challenges, a series of driverless vehicle races sponsored by the U.S. Government, Google was finally able to bring the driverless car phenomenon to reality.

The Google Car is a sophisticated system that integrates proprietary hardware and software, using video cameras, radar sensors, and a laser range finder to visualize traffic and detailed maps taken from Google Maps to enable navigation between destinations. Google's data centers process the incoming data relayed from the sensors and cameras mounted on the Google Car in order to provide the car with useful information about its environment that is later translated into the physical operation of the vehicle.

The key to the Google Car's technological capabilities is the laser range finder mounted on the roof of the modified Toyota Prius, allowing for real-time environmental analysis. In addition, the Google Car is equipped with four radars and a velodyne 64-beam laser placed strategically around the car to accurately generate a three dimensional map of its environment. A camera detects traffic lights while a GPS, wheel encoder, and inertial measurement unit control the vehicle's location and logs car movement (Guizzo, 2013). The software system synthesizes laser measurements produced from the laser beam with high-resolution maps of the world, producing dynamic data models then translated into the physical operation of the vehicle by the car's internal software system. Altogether, the system allows for seamless operation of the vehicle that adjusts to its dynamic environment without the intervention of a driver.

In addition to the generic driverless capability, the Google Car's system also adjusts for local traffic laws and environmental obstacles in real-time. For example, if the Google Car approaches a four-way intersection and senses that the driver with the right of way does not move, the Google Car inches forward slightly to indicate to other drivers the intentions of driving through the intersection.

Altogether, the technology and adaptation to local conditions not only allows for driverless transportation, but also increases safety on the road. Since its introduction, the Google Car has completed 200,000 miles of accident-free computer-led driving, beyond one incident that was arguably caused by another driver (Hyde, 2013). The road test results for the Google Car indicate that the Google Car obeys all of the rules of the road and adjusts to its dynamic environment in real-time with no problems. Thus, with this integrated technology, the car has the capability of being safer than a human driver. 


\section{COMPETITORS}

Many traditional car manufacturers have also researched and invested resources into developing driverless technology. For instance, General Motors and Mercedes-Benz have been experimenting with automated driving systems since the early 2000's. However, a majority of these manufacturers have only developed "driver-assisted" technology, which automates certain elements of the driving experience without providing a completely driverless capability.

\section{General Motors (GM)}

General Motors (GM) has been developing driverless-type technology in both the Chevrolet and Cadillac lines. Working alongside Carnegie Mellon University, GM has modified a Chevrolet Tahoe to include the basic capabilities of driverless functionality. Mass production of these vehicles is estimated to be ten years away. GM has also explored driverless technology in its Cadillac brand. While Cadillac is not exploring a driverless technology specifically, a semi-automatic prototype - the "Super Cruise" - is being tested (Crider, 2013). The modified Cadillac's driverless technology only operates in congestion and highway situations. Estimated integration dates into Cadillac's existing Cadillac User Experience (CUE) system are projected for the middle 2010's. Thus, while GM's projects in driverless technology are not yet completely realized, as CEO Rick Wagoner has explained, General Motors will continue to develop its vehicle-to-vehicle communications that will "minimize traffic jams and, more importantly, greatly reduce traffic accidents and fatalities with minimal and possibly even no roadway infrastructure required" (Crider, 2013).

GM has not been the only manufacturer that has explored driverless technology. Luxury brands have also devoted years of effort and engineering into producing driver-assisted technologies. Those with technology closest to realization are Mercedes-Benz and Bayerische Motoren Werke (BMW), as both companies have been working on driverless technology far longer than Google.

\section{Mercedes Benz}

Mercedes currently has a fleet of driverless vehicles based on the E-class and C-class models (Atkinson, 2013). Internal sensors, an advanced GPS, and distronic active cruise control guide the Mercedes through obstacles on the test tracks. A robotics system occupies the driver's seat and operates the steering wheel and pedals. While Mercedes has used this driverless technology for safety testing for years, the technology is not being considered for full integration into its automobiles as the driving experience is considered integral to the consumer choosing a high performance, luxury vehicle.

\section{Bayerische Motoren Werke (BMW)}

On February 28, 2013, BMW announced plans for an autonomous vehicle capable of traversing highways, intersections, toll stations, and roadwork (Maclean, 2013). In partnership with the parts supplier, Continental, the German automaker is developing an electronic co-pilot system. BMW intends to further develop its basic driver assistant programs to improve its automobiles' safety. Dr. Christoph Grote, Head of BMW's Group Research and Technology, explains that "with our vision of highly automated driving, we are already developing the technologies and methodologies for a range of cutting-edge driver assistance systems." BMW estimates that it will introduce driver-assisted prototypes by the end of 2014 and by 2020, all BMWs will contain self-driving technology.

\section{THE DRIVERLESS VEHICLE ENVIRONMENT}

\section{Car Accidents}

The profound costs of car accidents in the $21^{\text {st }}$ century remain a key impetus for the development of driverless technology. Approximately 1.24 million people globally die every year as a result of car accidents (World Health Organization, 2012). In the U.S. alone, an estimated 10.8 million automobile accidents with 36,000 deaths occur annually (Bureau of Transportation, 2009). Beyond the loss of life, the total economic cost of automobile 
accidents in the U.S. approaches $\$ 299.5$ billion annually, which includes medical costs, property damage, loss of productivity, legal costs, travel delays, and pain and loss of quality of life (American Automobile Association, 2012).

Driverless technology is meant to address these tremendous costs. Sebastian Thrun, the Google Car's lead developer software engineer, estimates that the Google Car can cut this number by $90 \%$ by creating an errorless, integrated driving fleet of Google Cars. Altogether, Google estimates that the Google Car can save over 30,000 lives, prevent over 2 million injuries, and save nearly \$270 billion per year in the U.S. in total accident-related costs.

\section{Commuting}

In addition to a reduction in car accidents, the Google Car may also have a significant effect on reducing commuting time. Google estimates that the Google Car can reduce the daily commuting time by roughly $90 \%$ by making better use of the roughly eighty percent of empty space on roads by forming faster, tighter car lines on freeways. A synchronized car line with less error allows the cars to travel closer together, allowing for more efficient utilization of space on roads. As Americans spend an average of fifty-two minutes every day commuting, this implies that the Google Car can reduce the average commute to roughly five minutes (Bureau of Transportation, 2009).

Beyond decreasing commuting time, more efficient road use can alleviate traffic congestion with estimates that congestion wastes roughly 4.8 billion hours and nearly 1.9 billion gallons of fuel in the U.S. annually. Approximately $\$ 6.63$ billion in fuel costs per year are lost, in addition to the roughly $\$ 93$ billion in lost productivity ${ }^{1}$. Furthermore, as global energy use is expected to increase by at least $35 \%$ in the next 25 years, energy saving technology will only become increasingly important (US Energy Information Administration, 2012).

In addition to decreasing the space needed and saving billions of dollars in fuel costs, the driverless car reduces car accidents and commuting time and enhances productivity by making car-sharing easier. While car sharing is not prevalent, especially in developed economies, the technological capabilities of the Google Car enable car sharing to be a more realistic option. First, self-parking and delivery reduces the time and energy needed to park and retrieve the car. In addition, the car saves energy and time by optimizing driving routes based on the destinations of the passengers in shared vehicle. As the car could both deliver itself to an individual when needed, and park itself in a remote area when not in use, this could improve car utilization by an estimated 10-75\% (AAA, 2013). In addition to saving time, splitting gas costs among a larger number of drivers can reduce the per-driver cost of car ownership. It is estimated that the car sharing capability has the potential to decrease costs per trip-mile by eighty percent when compared to personally owned vehicles (Burns et al., 2013).

\section{Legislation}

Several state legislatures have adopted bills that establish guidelines for driverless vehicle operation since the emergence of driverless prototypes. On September 25, 2012, the California Legislature signed into effect bill SB 1298, authored by Senator Alex Padilla. SB 1298 establishes safety and performance standards for cars operated by computers on California roads and highways, essentially allowing computer-driven cars to drive alongside manual drivers (Padilla, 2013). Following the passing of this bill, California became the third state to allow self-driving cars, after Nevada and Florida. After approval of SB 1298, Senator Padilla's office issued the following statement:

Thousands of Californian's tragically die in auto accidents each year. The vast majority of these collisions are due to human error. Through the use of computers, sensors and other systems, autonomous technology can analyze the entire $360^{\circ}$ driving environment more quickly and accurately and can operate the vehicle more safely. Autonomous vehicles have the potential to significantly reduce traffic fatalities and injuries. I envision a future that includes selfdriving cars. Establishing safety standards for these vehicles is an essential step in that process. Autonomous technology is not science fiction. We are living in the era of Moore's Law where every two years we double our computer processing speeds. This is allowing us to make exponential leaps in advanced technology. To a large extent, that progress has made self-driving cars possible sooner, rather than later (Padilla, 2013).

\footnotetext{
${ }^{1}$ At the national average of $\$ 3.49$ per gallon of fuel on September 21, 2013.
} 


\section{Opposition}

Opposition to driverless cars from consumer and interest groups has intensified as mass integration of driverless cars becomes an increasing reality. Google faces significant criticism from several consumer privacy groups who are concerned about how the Google Car will gather required data from its environment. The recent revelation that Google has been secretly gathering data on personal web activity since 2007 raises concerns regarding technological privacy (Jemima, 2010). Consumer advocacy groups have explicitly addressed the California Assembly's Transportation Committee on this issue, demanding that the state of California impose strict privacy regulations on driverless cars before cars are mass produced. John M. Simpson, the Consumer Watchdog's Privacy Project director, explains:

SB 1298 must be amended to provide that driverless cars gather only the data necessary to operate the vehicle and retain that data only as long as necessary for their operation. It should not be used for any additional purpose, such as marketing or advertising, without the consumer's explicit opt-in consent. (Carter, 2013)

In addition, lobbying groups representing the largest automakers have vocally opposed the passing of SB 1298 on the basis that the bill allows companies and individuals to modify existing cars with potentially faulty technology. Under the bill, automakers would not be legally shielded from lawsuits that result from these faulty technologies, thereby placing liability on the automakers. Lobbying groups are concerned that "They're [driverless technology] not all Google and they could convert our vehicles in a manner not intended" (Efrati, 2013). In many states other than California, pressure from interest and lobbying groups has resulted in the indefinite postponement of legislation allowing for autonomous vehicles operation on public roads.

Critics also point to the fact that the Google Car may likely change the very nature of several industries, while bankrupting others. Experts believe that the technology of the Google self-driving car will become jobeliminating technology (MIT, 2011). With the progression of driverless vehicles, individuals whose livelihoods depend on driving, such as taxi or long-distance trucking, may see reduced opportunities for employment and eventually cease to exist (Naughton, 2012). The reduction in the demand for labor in these industries may also impact macroeconomic conditions, potentially increasing unemployment across several industries over time. Rendering entire industries vestigial is even more threatening to the economy given the instability and slow-growth equilibrium post-2008.

\section{THREATENED INDUSTRIES}

\section{Decreased Accidents}

As mentioned earlier, Google Car and the adoption of driverless technology threaten to fundamentally change a wide spectrum of industries, including insurance, health care, construction, transportation, and energy. In addition, government financing may be negatively affected by the widespread use of the Google Car.

Auto insurers may perhaps be the most significantly impacted companies, as they currently collect over $\$ 200$ billion in personal automotive premiums every year in the U.S. (Forbes, 2013). Initially, the payments to insurance customers would actually decrease as the number of accidents would decline. In the long run, however, premiums paid by customers would drop by approximately ninety percent as a result of lack of accidents, dramatically decreasing insurance company revenues and threatening profitability. In addition, the healthcare industry would also change drastically as a result of less car accidents. Losing millions of patients would mean billions of dollars in lost revenue.

In addition to insurance and health care, government finances could be significantly affected by the widespread adoption of the Google Car. More efficient, safe driving devoid of human error would effectively eliminate all traffic tickets and associated fines. In addition, greater adherence to traffic laws would decrease the demand for highway patrol officers. The taxi and trucking industry could see a similar decrease in demand for drivers if the Google Car technologies were adapted to taxis and trucks. 
Construction companies that maintain and build roads could also be impacted as the Google Car can function on much narrower roads, implying less materials needed. Producers of cement and asphalt would see similar revenue effects. Utility companies would also be negatively impacted as the need for traffic lights would eventually be eliminated since the entire Google Car fleet would be synchronized, thus allowing for a continuous flow of cars within intersections.

Furthermore, as mentioned earlier, the Google Car may decrease the need for urban parking, as Google cars can self-park in more remote areas. This would not only lead to a decrease in demand for city parking lots, but could also contribute to a decline in urban property values. Revenues from commercial parking lots would also decline as less city parking is needed.

\section{Decreased Transportation}

Finally, decreased transportation and improved efficiency could have a marked effect on the oil industry. As Google Cars can operate more efficiently due to better space utilization and elimination of human error, large drops in gasoline revenue would result. In addition to the decrease in gasoline needed as a result of technological innovation, the physical aspect of the design may also contribute to decreasing gas consumption in the Google Car. By allowing driverless cars to operate at extremely close proximity to one another, the Google Car technology promotes an aerodynamic process known as drafting. Drafting is the creation of a pocket of low pressure, or slipstream behind a moving vehicle that allows a second car to fall into a slipstream created by the first car and reduce air drag, thereby saving energy. Drafting alone could save approximately twenty percent in fuel consumption (Alter, 2007).

With $\$ 450$ billion related to crashes, $\$ 200$ billion in car insurance premiums, $\$ 600$ billion in car sales, hundreds of billions in health insurance premiums and energy, it is estimated that there is approximately $\$ 2$ trillion in annual revenue associated with automobile purchase, maintenance, and use in the United States alone. With a fleet of Google Cars, approximately $90 \%$ - or $\$ 1.8$ trillion - in total revenues annually may virtually disappear.

\section{CONCLUSION}

The Google Car has the potential to have a profound effect on energy consumption, efficiency, and traffic accidents. With subsequent productivity increases, and decreases in costs, the Google Car represents a potentially revolutionizing technology. It is precisely this potential, however, that creates a threat for Google to sustaining a long-term competitive advantage in the driverless car space. As the Google Car may radically shift the structure of affected industries and raises serious privacy concerns, vulnerable industries and consumer groups threaten the viability of the project. Thus, the Google Car faces challenges far greater than competing car manufacturers alone. In squaring off against politically and economically powerful industries that are facing their demise, can the Google Car survive? Can the will to revolutionize driving outweigh the costs of potentially ruined industries and massive unemployment? Who will win the war of the road?

\section{AUTHOR INFORMATION}

Sharon Poczter is an Assistant Professor of managerial economics in the Charles H. Dyson School of Applied Economics and Management at Cornell University. Her research examines the impact of government policy on firm level financial outcomes. Website: www.sharonpoczter.com E-mail: sharon.poczter@cornell.edu (Corresponding author)

Luka Jankovic is an undergraduate student in the Charles H. Dyson School of Applied Economics and Management at Cornell University. His primary interests are finance, investing, and strategy. E-mail: $\underline{\text { lmj57@ cornell.edu }}$

\section{REFERENCES}

1. Alter, L. (2007). Drafting effects. TreeHugger. Retrieved from http://www.treehugger.com/cars/draftingbehind-trucks-does-it-work.html 
2. American Automobile Association. (2011). Crashes vs. congestion what's the cost to society. American Automobile Association. Retrieved from http://newsroom.aaa.com/wpcontent/uploads/2011/11/2011_AAA_CrashvCongUpd.pdf

3. Atkinson, M. (2012). Driverless test cars and high-tech motors: A glimpse into benz's future. MSN Auto. Retrieved from http://autos.ca.msn.com/editors-picks/article.aspx?cp-documentid=24243904

4. Brynjolfsson E., \& McAfee, A. (2011). Winning the race with ever-smarter machines. MIT Sloan Management Review. Retrieved from http://sloanreview.mit.edu/article/winning-the-race-with-eversmarter-machines/

5. Bureau of Transportation. (2009). Data and statistics. Bureau of Transportation. Retrieved from http://www.rita.dot.gov/bts/node/11792

6. Burns, L., Jordan, W., \& Scarborough, B. (2013). Transforming personal mobility. The Earth Institute at Columbia University. Retrieved from http://sustainablemobility.ei.columbia.edu/files/2012/12/Transforming-Personal-Mobility-Jan-2720132.pdf

7. Carter, M. (2012). Consumer watchdog group raises opposition to google's driverless cars. Inhabitat. Retrieved from http://inhabitat.com/consumer-watchdog-group-raises-opposition-to-googles-driverlesscars/

8. Chunka, M. (2013). Google's trillion-dollar driverless car. Forbes. Retrieved from http://www.forbes.com/sites/chunkamui/2013/01/24/googles-trillion-dollar-driverless-car-part-2-the-rippleeffects/

9. Crider, M. (2012). The driverless cars that want to run google off the road. The Guardian. Retrieved from http://www.slashgear.com/the-driverless-cars-that-want-to-run-google-off-the-road-08226819/

10. Efrati, A. (2012). Google's driverless car draws political power. Wall Street Journal. Retrieved from http://online.wsj.com/article/SB10000872396390443493304578034822744854696.html

11. Google (2013). Our history in depth. Google. Retrieved from http://www.google.com/about/company/history/

12. Graziano, D. (2012). Android projected to own the smartphone market for the next four years. Yahoo. Retrieved from http://news.yahoo.com/android-projected-own-smartphone-market-next-four-years213256656.html

13. Guizzo, E. (2011). How Google's self-driving car works. IEEE Spectrum. Retrieved from http://spectrum.ieee.org/automaton/robotics/artificial-intelligence/how-google-self-driving-car-works

14. Hyde, J. (2011). This is google's first self-driving car crash. Jalopnik. Retrieved from http://jalopnik.com/5828101/this-is-googles-first-self+driving-car-crash

15. Kiss, J. (2010). Google admits collecting wi-fi data through street view cars. The Guardian. Retrieved from http://www.theguardian.com/technology/2010/may/15/google-admits-storing-private-data

16. Naughton, J. (2012). Google's self-guided car could drive the next wave of unemployment. The Guardian. Retrieved from http://www.theguardian.com/technology/2012/sep/30/google-self-driving-carunemployment

17. Padilla, A. (2012). California legislature approves driverless vehicle bill - senator padilla's legislation establishes performance and safety standards. Retrieved from http://sd20.senate.ca.gov/news/2012-08-29california-legislature-approves-driverless-vehicle-bill-senator-padilla-s-legislatio

18. Maclean, A. (2013). BMW's driverless car. Drive.com.au. http://news.drive.com.au/drive/motornews/bmw-admits-philosophical-dilemma-with-driverless-cars-20130923-2u8v2.html

19. McCracken, H. (2010). Driverless cars - a brief history. Technologizer. Retrieved from http://technologizer.com/2010/10/09/google-self-driving-cars/

20. Miller, M. (2012). Google takes 67\% search engine market share. Search Engine Watch. Retrieved from http://searchenginewatch.com/article/2232359/Google-Takes-67-Search-Engine-Market-Share

21. Molla, M. (2012). Gmail finally beats hotmail, according to third-party. GigaOM. Retrieved from http://gigaom.com/2012/10/31/gmail-finally-beats-hotmail-according-to-third-party-data-chart/

22. Squatriglia, C. (2008). GM says electronics - including driverless cars - will 'reinvent the automobile.' Wired.com. Retrieved from http://www.wired.com/autopia/2008/01/gm-says-electro/

23. Texas A\&M Transportation Institute. (2012). Urban mobility information. Texas A\&M Transportation Institute. Retrieved from http://mobility.tamu.edu/ums/report/ 
24. US Census Bureau. (2012). Motor vehicle accidents and fatalities. US Census Bureau. Retrieved from http://www.census.gov/compendia/statab/

25. W3schools. (2013). Browser statistics. W3schools. Retrieved from http://www.w3schools.com/browsers/browsers_stats.asp

26. World Health Organization. (2013). Injuries, traffic. World Health Organization. Retrieved from http://www.who.int/topics/injuries_traffic/en/

27. U.S. Energy Information Administration. (2013). Independent statistics and analysis. U.S. Energy Information Administration. Retrieved from http://www.eia.gov/ 